УДК 159.9. 316.6

DOI: $10.17223 / 17267080 / 65 / 6$

\title{
М.П. Шульмин
}

Томский государственный университет систем управления и радиоэлектроники (Томск, Россия)

\section{Феноменологический анализ опыта психологической адаптации инвалидов}

Исследование выполнено при поддержке Министерства образования и науки РФ в рамках госзадания (проект 28.8279.2017/8.9).

Целью исследования является описание психологического феномена субъективной адаптации инвалидов. Феноменологический анализ их переживаний использовался для описания феномена субъективной адаптации и эмпирически выявил существенные признаки и динамическую структуру феномена субъективной адаптации инвалидов. Кроме того, результать показали, что субъективная адаптация лучше проходит у инвалидов без интеллектуальных нарушений и близко связана с развитием нарративной грамотности инвалидов.

Ключевые слова: субъективная адаптачия; субъективное благополучие; инвалид; психологический феномен; нарративная грамотность.

\section{Введение}

Психосемантический конструкт «инвалидность-полноценность» один из компонентов содержания субъективности человека в мире социальных отношений современного исторического периода. Мир реальных социальных отношений существует как объективированный, ориентированный на «нормальное» психофизическое функционирование, проявленный во внешнем плане общения и деятельности индивидов. Общение и деятельность индивидов являются необходимыми условиями их субъективного благополучия, так как через них происходит реализация потребностей, начиная от физиологических и заканчивая потребностями в принятии и уважении. Согласно обозначенному выше конструкту, с инвалидом невозможно построить «полноценных» семейных, трудовых, партнерских и тому подобных отношений, в которых могли бы удовлетворяться потребности в безопасности, любви и т.д. В практике консультирования инвалидов у некоторых из них было выявлено нежелание вступать в семейные отношения с себе подобными партнерами. Однако существует достаточное количество других примеров, когда инвалиды становятся активными участниками разнообразных социальных отношений. Возникает вопрос: какие факторы детерминируют такие различия? Целью данного исследования стало описание феномена субъективной адаптации инвалидов как фактора, определяющего различия в их образе жизни. 


\section{Обзор литературы}

Очевидным, на первый взгляд, является наличие связи между материальными условиями жизни и субъективным благополучием инвалида, но на самом деле эта связь требует и доказательства, и уточнения. Определенные индивиды с позитивными материальными условиями могут негативно переживать свое субъективное благополучие (диссонанс или дилемма неудовлетворенности), а другие индивиды с негативными материальными условиями могут переживать позитивное субъективное благополучие (адаптация или парадокс удовлетворенности) [1. Р. 181]. Ведущие модели субъективного благополучия указывают на способность людей адаптироваться к любым жизненным событиям, включая инвалидность; эта способность в литературе называется гедонистической адаптацией [2. Р. 76; 3. Р. 310]. Люди с полной адаптацией могут вернуться на уровень благополучия, существовавший до наступления инвалидности. Многие защищают данную гипотезу адаптации, утверждая, что уровни субъективного благополучия (счастья) колеблются вокруг биологически детерминированных (заданных) значений, которые остаются практически неизменными [2. Р. 77; 4. Р. 24]. Данное утверждение поддерживается многими исследованиями, которые указали на личностные черты индивидов, имеющие значимую корреляцию с изменениями в уровнях субъективного благополучия (счастья) [5. Р. 293]. Люди в материально бедных жизненных условиях могут не иметь низкого уровня субъективного благополучия, если другие социальные отношения компенсируют их материальную депривацию [6. Р. 350; 7. Р. 194]. Но существуют и другие работы, которые противоречат гипотезам адаптации.

Недавнее исследование по выявлению связи между инвалидностью и благополучием опиралось на сложный оценочный инструмент и подтвердило, что полученные результаты противоречат гипотезам гедонической адаптации. Например, исследование показало, что долговременный уровень субъективного благополучия изменяется и адаптация не является неизбежным феноменом. Адаптируются люди или нет, возвращаются ли назад к изначальному уровню их благополучия и как быстро это происходит - зависит от разных типов событий. Дополнительно к этому существует значительное разнообразие в адаптации среди индивидов: одни адаптируются быстро, другие медленно [2. Р. 78].

Следуя A.J. Oswald и N. Powdthavee [4. Р. 17], идея адаптации может быть представлена следующим образом. Предполагаемый материальный доход представляется через простую функцию:

$$
\mathrm{V}=\mathrm{V}(\mathrm{Y})+\mathrm{H},
$$

где $\mathrm{V}($.$) - возрастающая кривая домашних доходов; Y и \mathrm{H}$ - измерители здоровья. После инвалидности на временном промежутке $\mathrm{T}$ благополучие снижается: $\mathrm{V}(\mathrm{Z})+\mathrm{H}-\mathrm{D}$, где $\mathrm{D}$ является бесполезностью после инвалидности, $\mathrm{Z}$ представляет доход после инвалидности (может включать смену работы). Чтобы не упустить идею адаптации, определим функцию науче- 
ния: $\mathrm{D}=\mathrm{D}(\mathrm{t}-\mathrm{T})$, где $\mathrm{t}$ представляет текущий временной период. Если адаптация, представляющая первую производную от функции $\mathrm{D}($.$) , стано-$ вится отрицательной, значит в длительный промежуток времени инвалидности данное влияние на благополучие снижается. Эта идея также может быть основанием для эмпирической проверки в российских условиях.

Однако, исходя из гуманистической методологии и используя принцип целостности для анализа поведения личности инвалида, необходимо учитывать не только объективные факторы адаптации, но и субъективное содержание его психики.

В первом приближении менее очевидной является связь субъективной адаптации с благополучием инвалидов. Субъективность - это психологическая основа бытия человека, его внутренняя жизнь, мир субъективных переживаний, «личная» реальность человека, в которой он живет наиболее подлинно (Дж. Бюджентал). Основные составляющие этой субъективной реальности - «наши образы восприятия, мысли, чувства и эмоции, ценности и предпочтения, предвидения и опасения, фантазии и мечты, а также все то, что бесконечно, днем и ночью, во сне и в бодрствующем состоянии происходит в нас, определяя то, что мы делаем во внешнем мире и что мы делаем из того, что там с нами случается» [8. Р. 7]. Субъективный мир не имеет таких ограничений, как наличие или отсутствие безбарьерной среды, общего языка для отражения картины мира и удовлетворения потребности в общении или обязательной необходимости в использовании средств технической реабилитации для включения в процесс совместной деятельности с условно здоровыми представителями культуры, в которой живет инвалид. Субъективный мир с позиции системного подхода является живой самоорганизующейся системой, структуры (элементы опыта) которой имеют свою топологическую представленность в сферах сознательного и бессознательного, пространства и времени, вступают в динамические взаимоотношения, имеют генетические свойства, включаются в биоэнергоинформационный обмен как внутри системы, так и с внешней средой и способны самовостанавливаться.

Субъективность - это, по выражению Дж. Бюджентала, «архетипическая родина» человека, откуда берет начало все самое важное в его жизни. И поэтому именно субъективность и происходящее в ней для исследователя исключительно важно - это, перефразируя Фрейда, «королевская дорога» постижения человеческого в человеке. Более того, настоящая, «жизнеизменяющая» психологическая работа возможна только в плоскости внутренней субъективной реальности. И чем серьезнее и острее проблема, над которой идет эта работа, тем основательнее необходимо погружение в субъективность «хозяина» проблемы - ему «не могут помочь никакие объективные манипуляции, сколько бы их ни было» [8. Р. 4]. Любая активность во внешнем по отношению к субъекту мире имеет значение постольку, поскольку она затрагивает его субъективность. Однако остается острым для исследователя вопрос о методе познания содержания субъективной реальности и происходящих в ней процессов. В проведенном ис- 
следовании феномена субъективной адаптации инвалидов был использован один из возможных ответов на данный вопрос.

\section{Метод исследования}

Исследование опыта субъективной адаптации проводилось методом феноменологического анализа переживаний участников целевой группы психологического клуба «Рефлексия», организованного в рамках деятельности Центра сопровождения студентов-инвалидов, структурного подразделения Томского государственного университета систем управления и радиоэлектроники. Целевой группой являются молодые инвалиды. Основной состав группы включает 12 молодых инвалидов, из которых 9 участников с нарушениями опорно-двигательного аппарата и 3 участника с нарушениями интеллекта.

\section{Результаты исследования}

В результате феноменологического анализа опыта субъективной адаптации инвалидов было выявлено, что феномен субъективной адаптации инвалидов проявляется в преобразовании их жизненного опыта. Результатом данного преобразования выступает изменение свойств нарративов, с помощью которых происходят структурирование инвалидами своего жизненного опыта и придание ему определенных смысловых значений. В процессе субъективной адаптации изменяется когерентность нарративов (они приобретают бо́льшую логическую целостность и взаимосвязанность), увеличивается их модальная сложность (активируются различные системы репрезентации жизненного опыта, такие как визуальная, аудиальная, кинестетическая, обонятельная, вкусовая и поведенческая), возникает дифференциация нарративов (нарративы относительно внешнего опыта переживаний, нарративы относительно внутреннего опыта переживаний и нарративы относительно опыта рефлексии над внешним и внутренним опытом переживаний).

Нарратив является основной динамической структурой, с помощью которой инвалиды конструируют смыслы в процессе субъективной адаптации. Результатом субъективной адаптации выступает возникновение большей целостности (нарративной упорядоченности), сложности (различные нарративные осмысления существуют в комплексе), разнообразия нарративов (множественность нарративного содержания). Субъективная адаптация ведет инвалида к усилению разнообразия нарративного содержания, осознанию вариативности нарративных осмыслений (развитие от экстернальности к большей интернальности и рефлексивности), к способности усиливать альтернативные направления создания связей между своими нарративами.

В динамическом аспекте феномен субъективной адаптации инвалидов имеет пять стадий: воспоминание, объективация, субъективация, ме- 
тафоризация и проектирование. На первой стадии инвалиды воспроизводят отношение к прошлому жизненному опыту (определенным жизненным событиям). На второй стадии происходит репрезентация внешнего опыта в образах различной сенсорной модальности, на третьей - репрезентация внутреннего опыта переживаний внешних событий в виде сопровождающих переживания мыслей и эмоциональных состояний. На четвертой стадии - метафоризации - происходит переосмысление опыта через конструирование метафор (изменение стереотипного значения опыта через идентификацию с новым контекстом). Пятая стадия - проектирование - определяет способность инвалидов изначально конструировать прототипичные нарративы с позитивной психосемантикой, влияющие на их субъективное благополучие в жизни.

При активизации нарративов в памяти инвалиды воспроизводят собственное отношение к опыту, учатся, каким образом использовать прошлый и текущий опыт как важное средство для создания смыслов. С помощью психологических упражнений инвалиды активируют в памяти значимые нарративы, анализируя свою жизнь, поделенную на временные интервалы, и отбирая некоторые из них для анализа. Предполагается, что отобранные нарративы будут являться прототипами или наилучшими примерами.

Например, участник О. обратила внимание на периодически повторяющийся в ее жизни опыт построения межличностных отношений с молодыми людьми противоположного пола. «Меня напрягают молодые люди, которые стремятся перевести дружеские отношения в разряд любовных. Мне эти попытки не нравятся, и я начинаю сводить отношения с этими молодыми людьми к минимуму. Я считаю, что дружба между женщиной и мужчиной невозможна».

Участник С. ставит акцент на периодически повторяющемся опыте взаимодействия с хулиганами, которые отбирают у него деньги, сотовый телефон или другие ценные вещи. «Они видят, что я инвалид и не могу противостоять им силой, подходят в наглую и начинают требовать деньги на проезд, сотовый телефон, чтобы типа позвонить. А я - инвалид, что я могу с ними сделать? Вот и не знаю, как поступать в таких ситуациях».

Участник К. (с нарушением интеллекта) вспоминает, что ее часто используют на различных мероприятиях. «Вот нашли дурочку! К. подай то, К. помой посуду и т.д. А я и так каждый раз все за всех делаю. Мне и мама говорит, чтобы я перестала все за всех делать. Пусть теперь ктонибудь другой посуду моет».

Вторая стадия - объективизация нарративов - помогает инвалидам в развитии объективизации отношения к опыту, позволяя им определить сенсорные и поведенческие измерения их нарративов (например, визуальные, аудиальные, обонятельные, вкусовые, кинестетические, поведенческие). В качестве результата не нужно добиваться объективности, фотографической точности, достоверной представленности опыта; вместо этого инвалиды побуждаются усилить сложность (комплексность) их онтологии с помощью осознания структуры опыта. Инвалиды получают инструкции в 
сфере развития объективизации отношения к опыту и обучаются практически применять этот глубокий анализ к отобранным ими прототипичным нарративам.

Например, участник С., выполняя задание, говорит: «Я вижу, как автобус приближается к моей остановке, слышу, как открываются двери. Я осторожно спускаюсь со ступенек автобуса, слышу пьяную речь этих хулиганов, чувствую запах дыма сигарет. Ощущаю, как ладони становятся влажными, мышцы - напряженными и дрожащими, дыхание - учащенным и поверхностным. Я стараюсь не смотреть на них, чтобы они меня не заметили, но слышу их окрик». «Смотря на себя их глазами, вижу беспомощного инвалида, слышу его учащенное дыхание. Его колени и руки трясутся, и он отворачивает голову в сторону. Чувствую поднимающееся возбуждение и азарт наживы. Начинаю двигаться в его сторону, чтобы догнать его, остановить и подчинить».

Третья стадия состоит из субъективизации нарративов. Идиосинкразичная природа каждого нарратива характеризуется внутренними переживаниями их свойств, одновременно возникают мысли и эмоции. Внутренняя сторона опыта передается нам как изначально драматическое средство создания смыслов для внешних нарративов. Инвалиды учатся, каким образом создавать нарративы их эмоциональных переживаний с помощью экспериментальных стратегий поведения, фокусировки и символизации. Дополнительно к этому они знакомятся с инструментами для создания когнитивных измерений для нарративов, такими как слушание мыслей и наблюдение за внутренним голосом. Оба этих процесса применяются к анализу отобранных прототипичных нарративов.

Например, участник К. воспроизводит содержание наставлений внутреннего голоса: «Я слышу внутри себя голос моей мамы, которая повторяет, что я должна отказаться снова мыть посуду за всеми. Если я не откажусь, то снова останусь дурочкой, которую используют все окружающие. Я должна показать им, что я не девочка на побегушках!»

Участник С. символизирует переживание эмоции страха перед хулиганами в образе дикой собаки. «Этот хищный зверь полностью контролирует меня, любое мое движение, любую мою мысль. И если я не подчинюсь этой твари, она разорвет меня на куски». Он также сообщает о результатах наблюдения за своими мыслями: «Эти подонки пользуются тем, что я беспомощный инвалид, если бы я был здоровым, то я бы показал им! Хоть бы они меня не заметили».

Во время прохождения предыдущих процессов субъективной адаптации инвалиды прогрессивно приближаются к эффективному созданию смыслов. Формирование смыслов является несомненной целью четвертой стадии субъективной адаптации - создания метафоры для нарративов. Метафоры рассматриваются как идеальные символы создания смыслов, которые являются изоморфными содержанию нарративов.

Например, участник Д. метафоризирует скандал между его родителями как очередную сцену в многосерийном фильме, зрителем которого он случайно оказался. 
После того как инвалиды обучились творчески создавать смысловые метафоры относительно своего элементарного опыта, они направляют внимание на прототипичные нарративы и получают инструкцию, как создать их центральную метафору (метафору прототипичного нарратива), в содержании которой должна происходить трансформация вербализации коммуникативного стресса в коммуникативный транс.

На данной стадии субъективной адаптации инвалиды конструируют прототипичный нарратив с объективацией когнитивных и поведенческих деталей, комплексом когнитивной и эмоциональной субъективизации и очерчиванием коренной смысловой метафоры. Дополнительно к этому они стремятся развивать способность усиливать свои нарративы с помощью создания смыслов для прошлого, текущего и приходящего опыта.

Например, участник О. вербализует свою прототипичную метафору следующим образом: «Я - побитая ураганом яблоня, ветви которой склонились к земле, но вскоре моя нестерпимая боль придаст мне силы и я расцвету!» На примере данной метафоры наглядно представлен переход из состояния стресса в состояние транса за счет изменения значения переживания нестерпимой боли. Словосочетание «нестерпимая боль» потенциально является полисемантичным, сочетающим одновременно позитивную и негативную коннотацию, проявление которой зависит от контекста метафоры.

На завершающей стадии проектирования смыслов для нарративов задачей является оказание помощи инвалидам в формулировании альтернативных смысловых метафор и проверке этих смыслов через проектирование новых нарративов. Завершающей задачей является направление инвалидов на возникающие в жизни нарративы и придание смыслов и собственного авторства активности. После этого инвалиды вовлекаются в проектирование отношения к опыту, чтобы развивать новые альтернативные характеристики (т.е. альтернативные метафоры), и в данный момент они развивают новые сценарии и экспериментируют с ними. Новые сценарии появляются из новых метафор. После определения смыслов с помощью новых метафор инвалиды вовлекаются в объективизацию и субъективизацию. Это приводит к тому, что инвалиды пробуют данные спроектированные нарративы, и опыт оценивается с помощью смыслов вновь разработанных нарративов.

Через процесс субъективной адаптации инвалиды вовлекаются в использование средств разработки своих новых нарративов как основного направления для повышения целостности, комплексности и многообразия их опыта. Это не означает достижение определенного нарратива, который устанавливает цель субъективной адаптации, но он усиливает инвалида с помощью определения и практического использования нарративных средств. Разработанные нарративные средства позволяют инвалидам никогда не завершать процесс создания нарративов как направление создания разнообразных смыслов их опыта.

Субъективная адаптация участников с нарушениями интеллекта требует дополнительного времени и индивидуальной формы психопрактиче- 
ской работы с психологом для прохождения каждого из этапов. Данную особенность можно объяснить задержкой в формировании нарративной грамотности у лиц с нарушениями интеллекта в процессе их онтогенеза. Существенную трудность для них составляет прохождение четвертой стадии - метафоризации, на которой психолог должен быть более активным в помощи лицам с нарушениями интеллекта при формулировании нарративных метафор.

\section{Обсуждение результатов исследования}

Таким образом, на основании результатов теоретического и феноменологического анализа можно утверждать, что жизнь инвалидов обусловливается множеством трудноопределимых детерминант и на первый взгляд кажется цепью случайных обстоятельств и совпадений. Пристальный взгляд исследователя, правда, может открыть за видимым переплетением событий некую закономерность или ряд причинно-следственных связей, но обыденное сознание инвалида, погруженное в собственное нерефлексируемое бытие, обычно теряется в море своих порывов, желаний и поступков, не видя их побудительных причин и не обнаруживая постоянно действующих факторов, формирующих жизнь инвалида.

Детерминанты человеческой жизни многообразны. Они действуют с различных уровней и имеют разную широту и степень влияния на благополучие инвалида. Хотя многие из них могут быть сведены во вполне ясные социальные, психологические, физиологические и иные категории, существенная их часть носит случайный характер, не являясь общей закономерностью, но в то же время зачастую определяющим образом влияя на фактуру жизни отдельного инвалида, его личную историю. Таковой может оказаться случайное замечание матери: «Да за какие же грехи ты так страдаешь!», - которое ненароком услышал и воспринял ребенок-инвалид и которое всю жизнь как бессознательное влияние определяет тот или иной аспект жизни уже взрослого человека. Таковыми могут оказаться отдельные факты личной биографии, в том числе травматического характера, к которым относится и наступление инвалидности.

Так или иначе, все они в своей совокупности формируют жизнь инвалида, определяя ее счастливые или ужасные моменты, успехи и падения, притяжения, отталкивания, амбивалентности, тактики и стратегии достижения и избегания и т.п. В то же время, в той степени, в какой удается осознать даже часть действующих причин, появляется возможность подойти к ним более осмысленно, выяснить возможности позитивного или негативного воздействия их на жизнь конкретного инвалида и определенным образом откорректировать это влияние.

Если рассмотреть различные жизненные стратегии инвалидов, то, с одной стороны, можно обнаружить картину жизни, обусловленную по большому счету бессознательными причинами и сформированную случайным образом: «жизнь так сложилась». С другой стороны, можно увидеть 
жизненный путь, в существенных своих моментах выстроенный самим человеком.

В любом случае, участвовал ли инвалид сознательно в той или иной степени в своей жизни или в основном пустил ее на самотек, она приобретает вполне определенную структуру социальных связей, мотиваций, представлений, распределения жизненной энергии, пространственной и временной организации собственного бытия и т.д. В обоих вариантах она может быть как успешной, так и неуспешной: как случайная (т.е. сознательно не задаваемая) детерминация жизненного пути может оказаться удачной и продуктивной или, наоборот, отягченной проблемами, так и сознательно формируемая с того или иного уровня осознавания судьба может оказаться неблагополучной и сложной или выстроенной весьма конструктивным образом. Во втором случае успешность определяется правильностью исходных посылок и соответствующих воздействий.

Как итог возникает феномен субъективной адаптации: жизнь инвалида может быть успешной, существуют субъективные факторы, определяющие ее успешность, они могут быть выявлены, проанализированы и сознательно и адекватно применены для выстраивания успешного жизненного пути. И хотя проверка данной гипотезы не была простой, она стала вполне возможной.

\section{Заключение}

Использование методологического принципа целостности гуманистической психологии в изучении личности российских инвалидов предполагает проверку гипотез о влиянии объективных факторов, таких как состояние современной культуры, характер и степень сложности инвалидности, время наступления и продолжительность жизни с инвалидностью, материальное положение и т.д., и проверку гипотез о влиянии факторов, связанных с субъективностью инвалидов, представленной подлинно человеческими феноменами переживания себя в мире, созданном для жизни условно здоровых индивидов. Результаты феноменологического исследования субъективной адаптации психологических структур (элементов опыта), составляющих содержание субъективности инвалида, имеют непосредственное значение для последующей организации практической психологической работы с инвалидами в России в рамках деятельности реабилитационных центров и психологических служб.

\section{Лumepamypa}

1. Olson G.I., Schober B.I. The Satisfied Poor: Development of an Intervention-Oriented Theoretical Framework to Explain Satisfaction with Life in Poverty // Social Indicators Research. 1993. № 28. P. 173-193.

2. Lucas R.E. Adaptation and the Set-Point Model of Subjective Well-3. being // Current Directions in Psychological Science. 2007. № 16 (2). P. 75-79. 
3. Lucas R.E., Scollon C.N. Beyond the Hedonic Treadmill: Revising the Adaptation Theory of Well-Being // American Psychologist. 2006. № 61 (4). P. 305-314.

4. Oswald A.J., Powdthavee N. Does Happiness Adapt? A Longitudinal Study of Disability with Implications for Economists and Judges // Discussion Paper 2208. Institute for the Study of Labor. Bonn, 2006.

5. Suh E.M., Lucas R.E., Smith H.L. Subjective Well-Being: Three Decades of Progress // Psychological Bulletin. 1999. № 125 (2). P. 276-302.

6. Biswas-Diener R., Diener Ed. Making the Best of a Bad Situation: Satisfaction in the Slums of Calcutta // Social Indicators Research. 2001. № 55. P. 329-352.

7. Biswas-Diener R., Diener Ed. The Subjective Well-Being of the Homeless and Lessons for Happiness // Social Indicators Research. 2006. № 76. P. 185-205.

8. Bugental J.F.T. The Art of the Psychotherapist. New York, 1987. 216 p.

Поступила в редакииио 20.06.2017 г.; повторно 28.07.2017 г.; принята 28.08.20172.

\section{Сведения об авторе:}

ШУЛЬМИН Максим Петрович, кандидат психологических наук, доцент кафедры истории и социальной работы Томского государственного университета систем управления и радиоэлектроники (Томск, Россия). E-mail: scoobi@inbox.ru

\section{SUBJECTIVE ADAPTATION OF THE DISABLED AS A PSYCHOLOGICAL PHE- NOMENON}

Shulmin Maksim P., Tomsk State University of Control Systems and Radioelectronics (Tomsk, Russian Federation). E-mail: scoobi@inbox.ru

Siberian journal of psychology, 2017, 65, 83-93. DOI: 10.17223/17267080/65/6

Key words: subjective adaptation; subjective welfare; disabled person; psychological phenomenon; narrative grammar.

The purpose of this study is to describe the psychological phenomenon of subjective adaptation of disabled people. The sample group consisted of 12 Russian-speaking young disabled persons who participate in a psychological club "Reflection", that was established within activity of Center of Disabled Students Support in Tomsk State University of Control Systems and Radioelectronics. There were 9 persons with locomotor disorders and 3 persons with intellectual disorders. We used the phenomenological analysis of their experience dynamics to describe the subjective adaptation phenomenon. Phenomenological analysis revealed the essential notes and dynamic structure of the phenomenon. Also, the results demonstrated that the subjective adaptation better occurs among disabled persons without intellectual disorders and is closely connected with the narrative grammar education of the disabled. The subjective adaptation described in the study is a multi-dimensional phenomenon. It occurs in experience narrative dimensions. On the other hand, the subjective adaptation presented in this study, is a new object of practical psychological work with disabled people. The subjective adaptation phenomenon can be an object for further research in the field of disabled people inner and social integration, it will also help to clarify the process of person development and understanding the cases of self-organization of the experience structural components of a disabled person.

In any case, whether a disabled person participated more or less consciously in his life or let the things drift, his life would assume a kind of structure. It includes social relationships, reasons, representations, life energy distribution, space and time arrangement of own existence, etc. In both cases, it can be successful or unsuccessful: as casual (i.e. consciously undefined) course of life determination might be successful and productive or aggravated by problems, as consciously shaped, from one or another level of reflection, fate might be unhappy 
and complicated or developed with very constructive method. In the second case, success is determined by rightness of presuppositions and correctness of corresponding influences.

As a result, the phenomenon of subjective adaptation appears. The life of a disabled person might be successful, there are subjective factors that determinate its effectiveness, and they might be revealed and analyzed. They might be correctly implemented for a happy course of life development. Though, to test this hypothesis was not easy, it was quite possible.

\section{References}

1. Olson, G.I. \& Schober, B.I. (1993) The satisfied poor: Development of an interventionoriented theoretical framework to explain satisfaction with life in poverty. Social Indicators Research. 28. pp. 173-93. DOI: 10.1007/BF01079657

2. Lucas, R.E. (2007) Adaptation and the set-point model of subjective well-being. Current Directions in Psychological Science. 16(2). pp. 75-79. DOI: 10.1111/j.14678721.2007.00479.x

3. Lucas, R.E. \& Scollon, C.N. (2006) Beyond the hedonic treadmill: Revising the adaptation theory of well-being. American Psychologist. 61(4). pp. 305-314. DOI: 10.1037/0003066X.61.4.305

4. Oswald, A.J. \& Powdthavee, N. (2006) Does Happiness Adapt? A Longitudinal Study of Disability with Implications for Economists and Judges. Bonn: Institute for the Study of Labour.

5. Suh, E.M., Lucas, R.E. \& Smith, H.L. (1999) Subjective well-being: Three decades of progress. Psychological Bulletin. 125(2). pp. 276-302. DOI: 10.1037/0033-2909.125.2.276

6. Biswas-Diener, R. \& Diener, Ed. (2001) Making the best of a bad situation: Satisfaction in the slums of Calcutta. Social Indicators Research. 55. pp. 329-352. DOI: 10.1023/A:1010905029386

7. Biswas-Diener, R. \& Diener, Ed. (2006) The subjective well-being of the homeless and lessons for happiness. Social Indicators Research. 76. pp. 185-205. DOI: 10.1007/s11205-005-8671-9

8. Bugental, J.F.T. (1987) The Art of the Psychotherapist. New York: W. W. Norton \& Company.

Received 20.06.2017;

Revised 28.07.2017;

Accepted 28.08.2017 